\title{
Structural properties of unconventional lead cuprate glass
}

\author{
S. Hazra and A. Ghosh \\ Solid State Physics Department, Indian Association for the Cultivation of Science, \\ Calcutta 700 032, India
}

(Received 17 October 1994; accepted 12 May 1995)

\begin{abstract}
Glass formation and structural properties of the unconventional lead cuprate glasses of compositions $(\mathrm{CuO})_{\mathrm{x}}(\mathrm{PbO})_{100-x}(\operatorname{mol} \%)$, are reported for the first time. $\mathrm{X}$-ray diffraction and electron microscopic studies show that the glass formation occurs for $x=$ 15-50 mol \%. The compositional dependence of the density, molar volume, and glass transition temperature suggests that all glass compositions in this domain have the same topology and network connectivity. The glass structure is built up of $\left[\mathrm{PbO}_{4}\right]$ tetrahedral units. On heat treatment above glass transition temperatures, the glasses crystallize to $\mathrm{CuO}$ and $\mathrm{PbO}$. Electron Spin Resonance (ESR) spectra of the glass compositions consist of broad resonance lines.
\end{abstract}

\section{INTRODUCTION}

Oxide glasses based on $\mathrm{PbO}$ are of great interest because they can form amorphous materials without traditional network formers like $\mathrm{SiO}_{2}$, and they can be used to produce glass ceramics, layers for optical and optoelectronic devices, thermal and mechanical sensors, and reflecting windows. ${ }^{1-4}$ However, few studies have been reported on the $\mathrm{PbO}$-based glasses., 5 Lead and bismuth oxides can be incorporated in high concentration in the glasses based on traditional network formers. ${ }^{7,8}$ It was pointed out that $\mathrm{Pb}^{+2}$ cations are highly polarizable and the asymmetry of their polyhedra inhibits crystallization processes in the melts in which they participate. In silicate glasses when lead oxide is added, $\mathrm{PbO}$ acts as a network modifier for low concentration, while at high concentration, it is capable of participating in the network. ${ }^{8}$ Nuclear magnetic resonance studies ${ }^{9}$ confirm the 4-coordination of lead in high $(>50 \mathrm{~mol} \%) \mathrm{PbO}$ glasses. Recently, glasses in which $\mathrm{PbO}$ is the main network former have been synthesized and their structures have been studied. ${ }^{1,10-12}$

The purpose of the present paper is to study the glass formation domain and structure of the binary $\mathrm{CuO}-\mathrm{PbO}$ glasses, using $\mathrm{PbO}$ as the basis of the glass network former instead of conventional glass-forming oxides.

\section{EXPERIMENTAL PROCEDURE}

Samples of compositions $(\mathrm{CuO})_{x}(\mathrm{PbO})_{100-x}$, where $x=15-50$ mol \%, were prepared using reagent grade chemicals $\mathrm{PbO}$ (Koch Light, UK) and $\mathrm{CuO}$ (Loba, India). The mixtures of these chemicals were melted in alumina crucibles in the temperature range $1100-1250{ }^{\circ} \mathrm{C}$ for $1 \mathrm{~h}$, as it was observed that the melts were highly homogeneous after $1 \mathrm{~h}$. Glassy samples were obtained by quenching the melts using a twin roller technique. ${ }^{13}$ $\mathrm{X}$-ray diffraction patterns of the powder samples as prepared and heat-treated at different temperatures for different durations of time were recorded in a x-ray diffractometer (Philips, model PW 1840). The scanning electron micrographs of the polished surfaces of the samples were taken in a scanning electron microscope (Hitachi, model S-415A). A $\sim 150 \AA$ thick gold coating was deposited on the polished surfaces of the samples by vacuum evaporation for conducting layers. The atomic absorption was carried out in an atomic absorption spectrometer (Varian, model AA 1475) to determine the final glass compositions, as well as to estimate the total copper ion concentrations. The density of the samples was

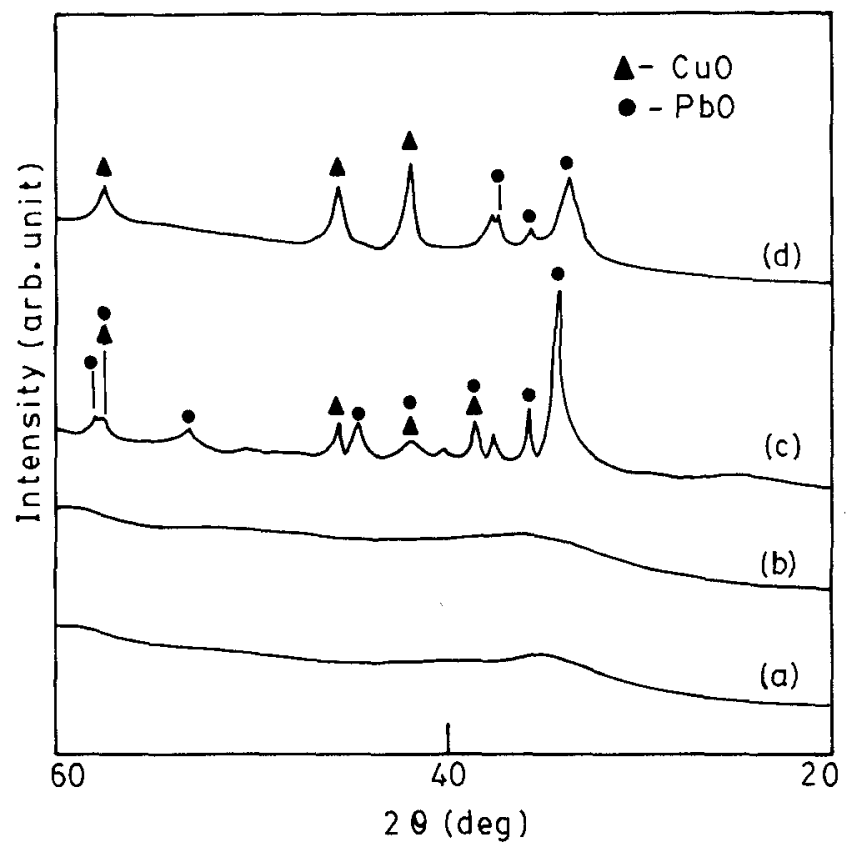

FIG. 1. X-ray diffractograms of several samples: (a) $29.53 \mathrm{~mol} \%$ $\mathrm{CuO}$, (b) $50.55 \mathrm{~mol} \% \mathrm{CuO}$, (c) $29.53 \mathrm{~mol} \% \mathrm{CuO}$ heat-treated at $650{ }^{\circ} \mathrm{C}$ for $15 \mathrm{~h}$, and (d) $50.55 \mathrm{~mol} \% \mathrm{CuO}$ heat-treated at $500{ }^{\circ} \mathrm{C}$ for $20 \mathrm{~h}$ 


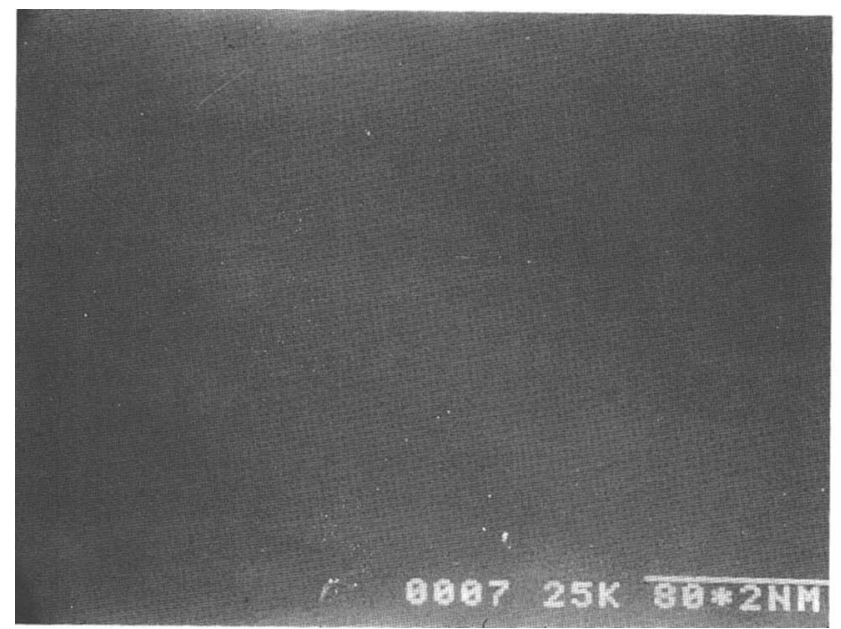

(a)

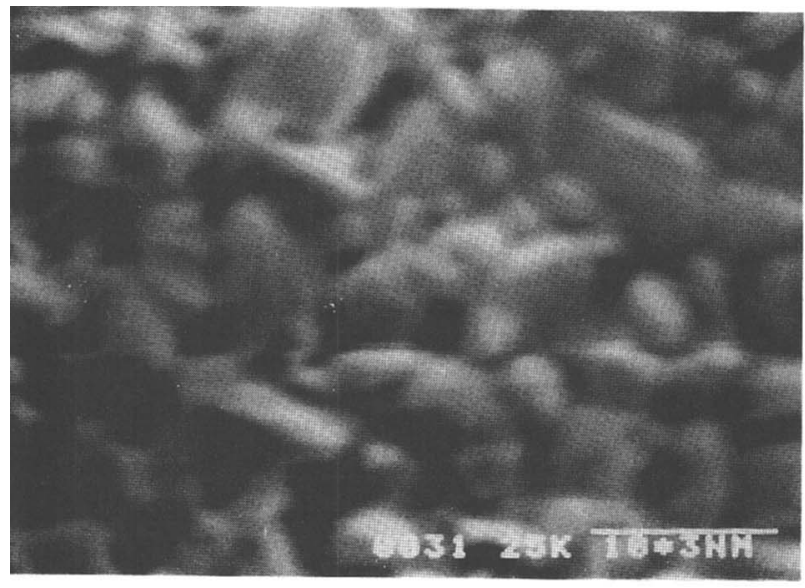

(c)

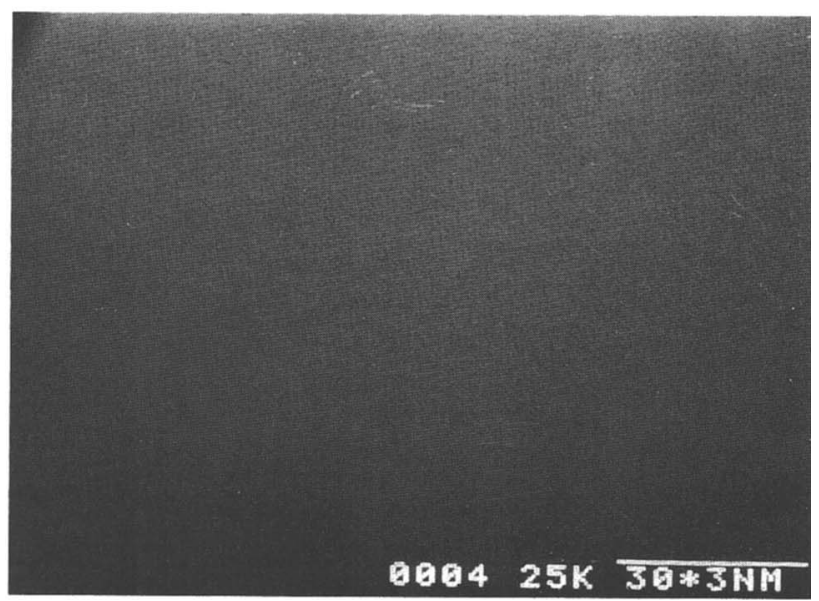

(b)

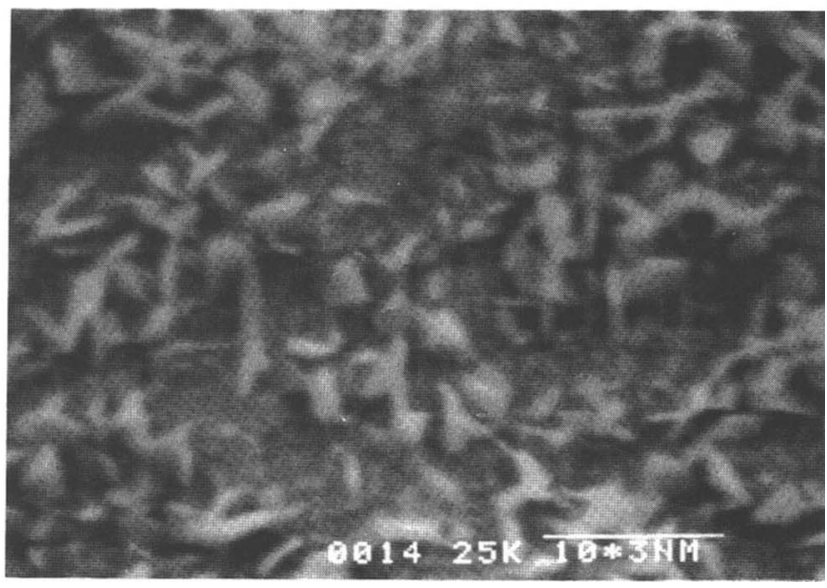

(d)

FIG. 2. Scanning electron micrographs of several samples: (a) $29.53 \mathrm{~mol} \% \mathrm{CuO}(\times 1000)$, (b) $50.55 \mathrm{~mol} \% \mathrm{CuO}(\times 3750),(\mathrm{c}) 29.53 \mathrm{~mol} \%$ $\mathrm{CuO}$ heat-treated at $500{ }^{\circ} \mathrm{C}$ for $20 \mathrm{~h}(\times 3000)$, and (d) $50.55 \mathrm{~mol} \% \mathrm{CuO}$ heat-treated at $500{ }^{\circ} \mathrm{C}$ for $20 \mathrm{~h}(\times 3000)$

measured at room temperature by Archimedes principle using acetone as the immersion liquid. Differential thermal analysis (DTA) was performed in air atmosphere for all samples using a thermal analyzer (Shimadzu, model DT-40). Infrared (IR) spectra of the prepared samples, as well as starting chemicals in $\mathrm{KBr}$ matrices, were recorded at room temperature in a spectrophotometer (Perkin-Elmer, model 783) in the wave number range $200-4000 \mathrm{~cm}^{-1}$. The concentration of $\mathrm{Cu}^{2+}$ ions was determined from the magnetic susceptibility measurement in a vibrating sample magnetometer (EG \& G Parc, model 155) at room temperature. The ESR spectra of the samples were recorded in an X-band ESR spectrometer (JEOL, model JES-RE1X) at room temperature.

\section{RESULTS AND DISCUSSION}

\section{A. Glass formation domain}

Glass formation domain of the binary $\mathrm{CuO}-\mathrm{PbO}$ system was determined by $\mathrm{X}$-ray diffraction and scanning electron microscopy. Figure 1 shows the x-ray diffractograms of two glass samples. The presence of broad diffuse scattering at low angles indicates the amorphous nature of the samples. In this way, glass formation in the binary $(\mathrm{CuO})_{x}(\mathrm{PbO})_{100-x}$ system was confirmed for $15-50 \mathrm{~mol} \% \mathrm{CuO}$. It is worth mentioning that the glass formation range for the binary system is much wider than the multicomponent PbO-based glasses. ${ }^{5,6}$ The $X$-ray diffractograms of two heat-treated samples are also shown in Fig. 1. The diffractograms of these heattreated samples exhibit crystalline peaks corresponding to the crystalline $\mathrm{PbO}$ and $\mathrm{CuO}$.

The scanning electron micrographs of several asprepared and heat-treated samples are shown in Fig. 2. It may be noted that the micrographs of the as-prepared samples exhibit surfaces without microstructure, confirming the amorphous nature of the samples. The micrographs of the heat-treated samples show their crystalline structure. However, detailed studies of the homogeneity of the glasses will be reported later. 
TABLE I. Different physical parameters estimated from atomic absorption, density, and magnetic measurement for the lead cuprate glasses.

\begin{tabular}{|c|c|c|c|c|c|c|}
\hline \multicolumn{2}{|c|}{$\begin{array}{c}\text { Analyzed glass } \\
\text { composition }(\mathrm{mol} \%)\end{array}$} & \multirow[b]{2}{*}{ Density $\left(\mathrm{g} \mathrm{cm}^{-3}\right)$} & \multirow[b]{2}{*}{$N\left(10^{21} \mathrm{~cm}^{-3}\right)$} & \multirow[b]{2}{*}[\mathrm{Cu}^{+}]{$\left(10^{21} \mathrm{~cm}^{-3}\right)$} & \multirow[b]{2}{*}{$C\left(\left[\mathrm{Cu}^{+}\right] / \mathrm{N}\right)$} & \multirow[b]{2}{*}{$R(\AA)$} \\
\hline $\mathrm{PbO}$ & $\mathrm{CuO}$ & & & & & \\
\hline 84.94 & 15.07 & 9.39 & 4.22 & 3.10 & 0.74 & 6.18 \\
\hline 78.87 & 21.13 & 8.90 & 5.87 & 4.37 & 0.74 & 5.54 \\
\hline 70.47 & 29.53 & 8.28 & 8.15 & 5.75 & 0.70 & 4.97 \\
\hline 64.24 & 35.76 & 7.76 & 9.73 & 7.13 & 0.73 & 4.68 \\
\hline 49.45 & 50.55 & 6.67 & 13.44 & 9.88 & 0.73 & 4.21 \\
\hline
\end{tabular}

\section{B. Analysed glass compositions}

Atomic absorption spectroscopic analysis shows that all glass compositions change slightly from the batch compositions due to evaporation loss of $\mathrm{PbO}$ during melting. The analyzed compositions are shown in Table I. These measurements, coupled with magnetic studies, indicate that copper ions exist in two oxidation states, e.g., $\mathrm{Cu}^{+}$and $\mathrm{Cu}^{2+}$ in all glass compositions. Table I shows that the concentration of the reduced copper ions $\left(\left[\mathrm{Cu}^{+}\right]\right)$increases consistent with the increase of total copper ion concentration $(N)$ in the glass compositions. However, the ratio $C$ of the concentration of the reduced copper ions to the concentration of the total copper ions is approximately constant for all glass compositions. The average intersite separation $(R)$ was estimated from the analyzed glass compositions and density. The values of $R$ (shown in Table I) are found to decrease with the increase of $\mathrm{CuO}$ content in the glass compositions.

\section{Density and molar volume}

The density and molar volume are shown in Fig. 3 as a function of composition. It may be noted that the density and the molar volume change smoothly with the glass compositions. This suggests that the topology of the glassy network does not change significantly with compositions. ${ }^{14}$ The composition dependence of the density and molar volume for the $\mathrm{CuO}-\mathrm{PbO}$ glasses may be compared with those of $\mathrm{CuO}-\mathrm{Bi}_{2} \mathrm{O}_{3}$ glasses. ${ }^{15}$ The decrease of density of the $\mathrm{CuO}-\mathrm{PbO}$ system with the decrease of $\mathrm{CuO}$ content in the compositions is more rapid than that for the $\mathrm{CuO}-\mathrm{Bi}_{2} \mathrm{O}_{3}$ system. The molar volume of the $\mathrm{CuO}-\mathrm{PbO}$ glasses increases, while the molar volume of the $\mathrm{CuO}-\mathrm{Bi}_{2} \mathrm{O}_{3}$ glasses decreases with the increase of $\mathrm{CuO}$ content in the glass compositions. ${ }^{15}$ Thus the structure of the $\mathrm{CuO}-\mathrm{PbO}$ glasses is much looser than that of the $\mathrm{CuO}-\mathrm{Bi}_{2} \mathrm{O}_{3}$ glasses. This is also evident from Table II which includes the molar volume for the ideal packing, calculated assuming that the molar volume of the glasses is simply a sum of the molar volumes of the crystalline $\mathrm{CuO}$ and $\mathrm{PbO}$. It may be observed that the molar volume of the glass compositions is higher than that for the ideal packing, except for

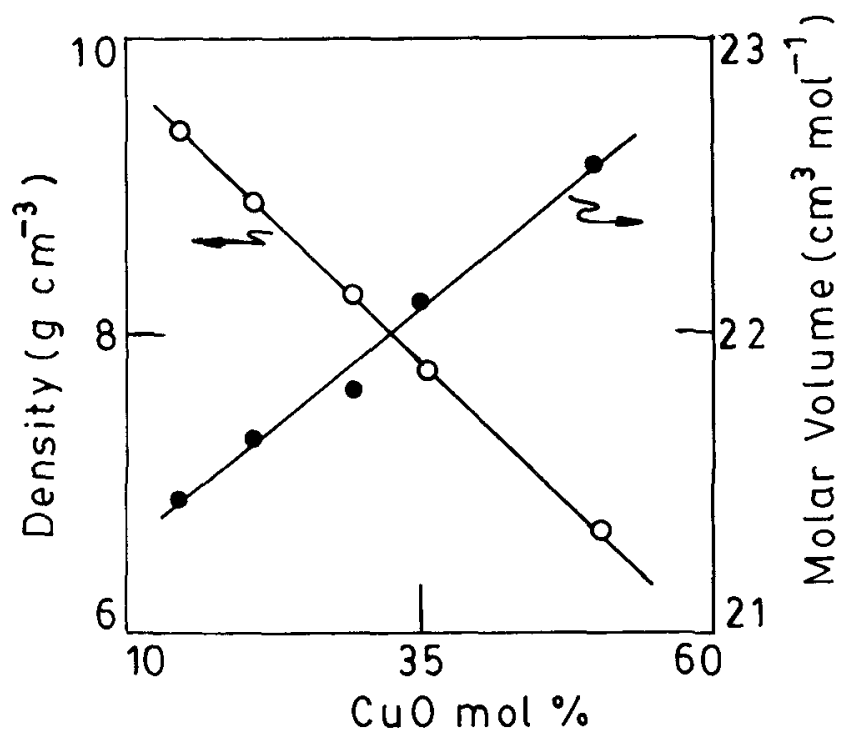

FIG. 3. Density (O) and molar volume (O) as a function of $\mathrm{CuO}$ content in the lead cuprate glass compositions.

the glass composition containing lowest $\mathrm{CuO}$. Also, the molar volume for the ideal packing decreases with the increase of $\mathrm{CuO}$ content in contrast to the trend observed for the molar volume of the glass compositions.

\section{Thermal analysis}

A typical differential thermal analysis curve for a glass composition is shown in Fig. 4, which exhibits an endothermic dip due to glass transition, followed by several exothermic peaks due to crystallizations. Other glass compositions also showed similar DTA features. The glass transition temperatures $\left(T_{g}\right)$ and the onset crystallization temperatures $\left(T_{c}\right)$ were estimated from the curves within an error of $\pm 5{ }^{\circ} \mathrm{C}$ and are shown in Table II. The compositional dependence of $T_{g}$ is shown in the inset of Fig. 4. It may be noted that $T_{g}$ increases very slowly with the increase of $\mathrm{CuO}$ content in the glass compositions. It thus suggests that the connectivity and strength of the glass network are almost the same in all compositions as supported by the composition dependence of the molar volume and density. A large difference $\left(\geqslant 30{ }^{\circ} \mathrm{C}\right)$ between the glass transition and 
TABLE II. Different physical parameters obtained from Table I and DTA analysis for the lead cuprate glasses.

\begin{tabular}{|c|c|c|c|c|c|c|c|}
\hline $\begin{array}{l}\text { Sample composition } \\
\text { mol \% CuO }\end{array}$ & $\begin{array}{l}\text { Molar volume } \\
\left(\mathrm{cm}^{3} \mathrm{~mol}^{-1}\right)\end{array}$ & $\begin{array}{l}\text { Molar volume for ideal } \\
\text { packing }\left(\mathrm{cm}^{3} \mathrm{~mol}^{-1}\right)\end{array}$ & $T_{g}\left({ }^{\circ} \mathrm{C}\right)$ & \multicolumn{4}{|c|}{$T_{c}\left({ }^{\circ} \mathrm{C}\right)$} \\
\hline 15.07 & 21.46 & 21.76 & 260 & 310 & 415 & 575 , & 600 \\
\hline 21.13 & 21.67 & 21.10 & 260 & 320 & 380 & 580 & 610 \\
\hline 29.53 & 21.83 & 20.17 & 265 & 320 & 370 & 590 & 610 \\
\hline 35.76 & 22.14 & 19.49 & 270 & 300 & 360 & 590 , & 610 \\
\hline 50.55 & 22.64 & 17.86 & 280 & 410 & 590 & 610 & \\
\hline
\end{tabular}

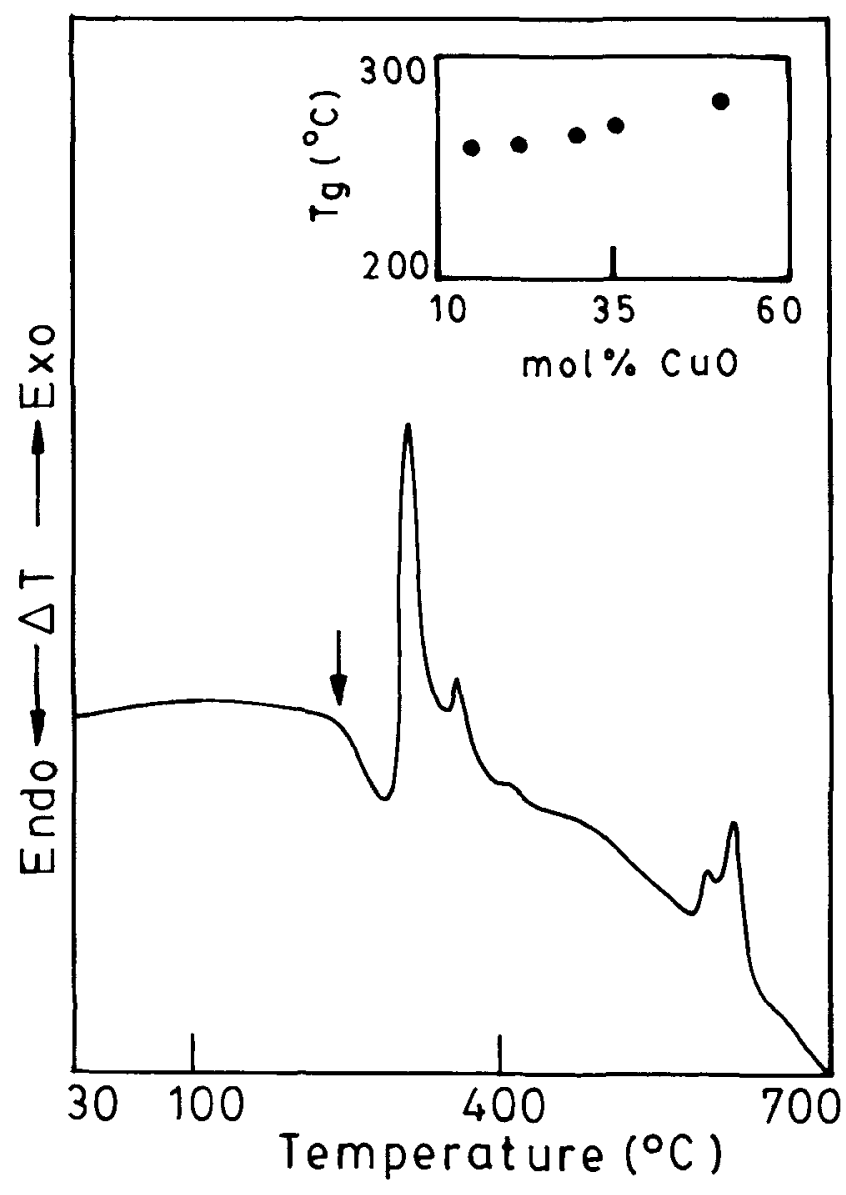

FIG. 4. Differential thermal analysis curve for a glass composition containing $29.53 \mathrm{~mol} \% \mathrm{CuO}$. Glass transition temperature is indicated by the arrow. Inset shows glass transition temperature $\left(T_{g}\right)$ as a function of $\mathrm{CuO}$ content.

crystallization temperatures indicates that the glasses are highly stable similar to the $\mathrm{CuO}-\mathrm{Bi}_{2} \mathrm{O}_{3}$ glasses. ${ }^{15}$

\section{E. Infrared spectra}

The infrared spectra at room temperature of all compositions are shown in Fig. 5. IR spectra of the crystalline $\mathrm{PbO}$ and $\mathrm{CuO}$ are also included in the figure for comparison. In all glass compositions, a strong IR band is observed at $\sim 610 \mathrm{~cm}^{-1}$. A broad absorption band at $\sim 830 \mathrm{~cm}^{-1}$ and weak shoulder in the range $450-500 \mathrm{~cm}^{-1}$ are also observed for all compositions.

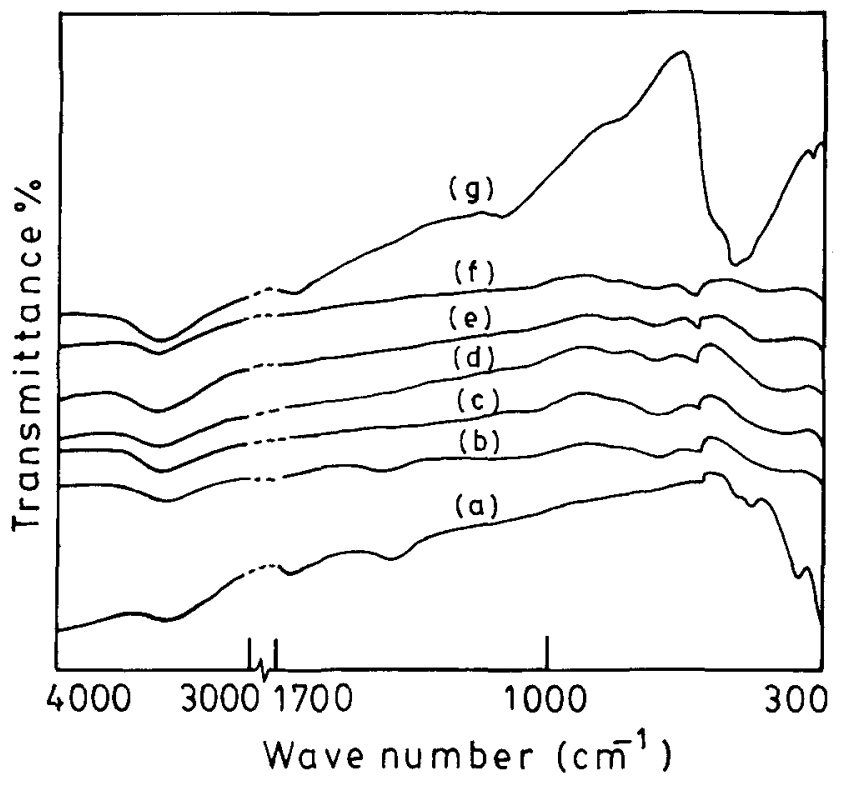

FIG. 5. Room temperature infrared spectra of several samples: (a) crystalline $\mathrm{PbO}$, (b) $15.07 \mathrm{~mol} \% \mathrm{CuO}$, (c) $21.13 \mathrm{~mol} \% \mathrm{CuO}$, (d) $29.53 \mathrm{~mol} \% \mathrm{CuO}$, (e) $35.76 \mathrm{~mol} \% \mathrm{CuO}$, (f) $50.55 \mathrm{~mol} \% \mathrm{CuO}$, and $(\mathrm{g})$ crystalline $\mathrm{CuO}$.

Comparison of the IR spectra of the glass compositions with those of the starting crystalline materials suggests that these bands correspond to the $\mathrm{Pb}-\mathrm{O}$ bond vibration in the $\left[\mathrm{PbO}_{4}\right]$ tetrahedral units. In the $\mathrm{IR}$ spectra, the presence of the characteristic bands of $\mathrm{CuO}$ is not observed. It may be mentioned that the structure of the $\mathrm{CuO}-\mathrm{PbO}$ glasses is different from that of the $\mathrm{CuO}-\mathrm{Bi}_{2} \mathrm{O}_{3}$ glasses, which consists of $\left[\mathrm{BiO}_{3}\right]$ pyramidal units. ${ }^{15}$

\section{F. Magnetic susceptibility and ESR spectra}

The magnetic susceptibility at room temperature of the glass compositions is shown in Table III and increases with the increase of $\mathrm{CuO}$ content in the glasses. The magnetic properties of these glasses arise from the paramagnetic $\mathrm{Cu}^{2+}$ ions with $3 d^{9}$ electron. The concentrations of the $\mathrm{Cu}^{2+}$ ions estimated from the susceptibility data increase consistent with the increase of the total copper ion concentrations in the glass compositions. 
TABLE III. ESR parameters and magnetic susceptibility data for the lead cuprate glasses.

\begin{tabular}{cccc}
\hline $\begin{array}{c}\text { Sample composition } \\
\text { mol \% CuO }\end{array}$ & $g_{e}$ & $\begin{array}{c}\Delta H_{p p} \\
\text { (Gauss) }\end{array}$ & $\begin{array}{c}\boldsymbol{X} \\
\left(10^{-7} \text { emu }\right)\end{array}$ \\
\hline 15.07 & $2.123 \pm 0.028$ & 280 & 2.50 \\
21.13 & $2.137 \pm 0.028$ & 300 & 3.54 \\
29.53 & $2.150 \pm 0.028$ & 380 & 6.08 \\
35.76 & $2.178 \pm 0.028$ & 440 & 7.05 \\
50.55 & $2.123 \pm 0.028$ & 360 & 11.31 \\
\hline
\end{tabular}

Figure 6 shows the room temperature ESR spectra of several glass compositions. From Fig. 6 it is clear that no hyperfine structure, but a broad single resonance line, is observed in the ESR spectra of the glasses. However, the glass compositions with higher $\mathrm{CuO}$ content (35.8 and $50.6 \mathrm{~mol} \% \mathrm{CuO}$ ) show unresolved hyperfine structure in the parallel components of the spectra only. Because of the unresolved nature of the spectra, it was not possible to extract hyperfine parameters. The effective $g$ values $\left(g_{e}\right)$ and the peak-to-peak linewidth $\left(\Delta H_{p p}\right)$ were estimated from the spectra and are shown in Table III. It may be noted that the effective $g$ values and peak-topeak width increase with the increase of $\mathrm{CuO}$ content in

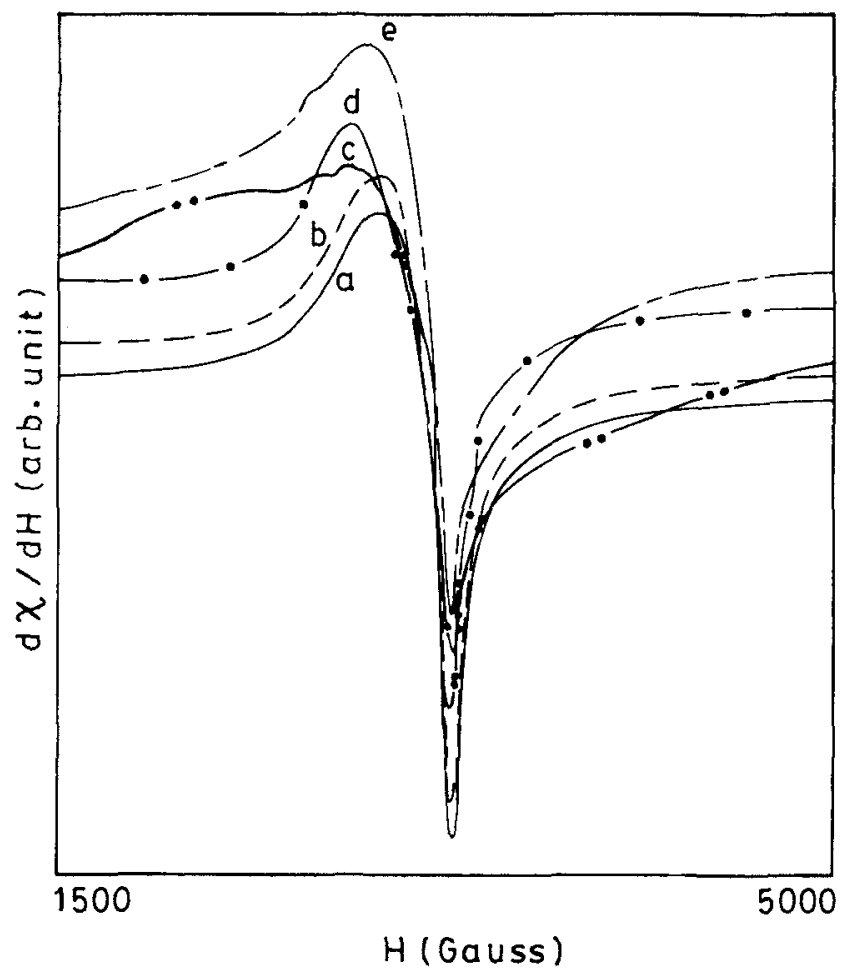

FIG. 6. Room temperature ESR spectra of lead cuprate glasses recorded at a microwave frequency of $9.45 \mathrm{GHz}$ : (a) $15.07 \mathrm{~mol} \%$ $\mathrm{CuO}$, (b) $21.13 \mathrm{~mol} \% \mathrm{CuO}$, (c) $29.53 \mathrm{~mol} \% \mathrm{CuO}$, (d) $35.76 \mathrm{~mol} \%$ $\mathrm{CuO}$, and (e) $50.55 \mathrm{~mol} \% \mathrm{CuO}$. the glass compositions with the exception of the composition containing the highest $\mathrm{CuO}$ content. A possible explanation for the absence of hyperfine structures in the glass compositions might be motional narrowing by the conduction electrons, whose concentrations increase with the increase of $\mathrm{CuO}$ content in the glasses. ${ }^{16}$ However, the increase of peak-to-peak width could be explained, assuming the existence of the clusters of copper ions in the glasses similar to $\mathrm{CuO}-\mathrm{Bi}_{2} \mathrm{O}_{3}$ glasses. ${ }^{15}$ The interaction between these clusters would give rise to broad ESR spectra.

\section{CONCLUSION}

Unconventional glasses in the $\mathrm{CuO}-\mathrm{PbO}$ system were first prepared by the rapid quenching of the melt. The x-ray diffraction and electron microscopic studies reveal the glass formation domain in the range $15-50 \mathrm{~mol} \% \mathrm{CuO}$. All the glass compositions in this domain have the same topology and network connectivity and are highly stable, as suggested by the composition dependence of the density, molar volume, and glass transition temperatures. The glasses, on heat treatment above glass transition temperatures, crystallize to $\mathrm{CuO}$ and $\mathrm{PbO}$. The ESR spectra of these glasses appear to be broad resonance lines which could arise from motional narrowing by the conduction electrons/interaction between clusters of copper ions.

\section{ACKNOWLEDGMENT}

S. H. acknowledges the University Grants Commission (India) for financial support.

\section{REFERENCES}

1. Y. Dimitriev, V. Mihanilov, and E. Gattif, Phys. Chem. Glasses 34, 114 (1986).

2. W. Mianxue and Z. Peinan, J. Non-Cryst. Solids 84, 344 (1986).

3. Y. Takahashi and K. Yamaguchi, J. Mater. Sci. 25, 3950 (1990).

4. M. Aegerter, E. Serra, A. Rodrignes, G. Kordas, and G. Moore, in Proceedings of Sol-Gel Optics, Julio, San Diego (SPIE, 1990).

5. W. H. Dumbaugh, Phys. Chem. Glasses 19, 121 (1978).

6. W. H. Dumbaugh, Phys. Chem. Glasses 27, 119 (1986).

7. K. Fajans and N. J. Kreidl, J. Am. Ceram. Soc. 31, 105 (1948).

8. J.E. Standworth, J. Soc. Glass Tech. 32, 154T (1948).

9. P. J. Bray, in The Structure of Glass, Proc. 4th All-Union Conference of the Glassy State, Part II (Consultants Bureau, New York, 1966), p. 52.

10. B. G. Rao and K. J. Rao, Phys. Chem. Glasses 25, 11 (1984).

11. K. J. Rao, J. Wong, and B. J. Rao, Phys. Chem. Glasses 25, 57 (1984).

12. H. Morikawa, J. Jegoudey, C. Mazieres, and A. Revcolevschi, J. Non-Cryst. Solids 44, 107 (1981).

13. H. S. Chen and C. E. Miller, Rev. Sci. Instrum. 41, 1237 (1970).

14. C. F. Drake, J. A. Stephan, and B. Yates, J. Non-Cryst. Solids 28 , 61 (1978).

15. S. Hazra and A. Ghosh, Phys. Rev. B. 51, 851 (1995).

16. S. Hazra and A. Ghosh, J. Chem. Phys. (in press). 